\title{
Impact of Climate Variability on Human Health in Ilorin, Nigeria
}

\author{
Tunde, A. M. ${ }^{1}$, Adeleke, E. A. ${ }^{1} \&$ Adeniyi, E. E. ${ }^{1}$ \\ ${ }^{1}$ Department of Geography \& Environmental Management, University of Ilorin, Nigeria \\ Correspondence: Tunde, A. M., Department of Geography \& Environmental Management, University of Ilorin, \\ Nigeria. E-mail: afolabi@unilorin.edu.ng
}

Received: November 26, 2012 Accepted: January 6, 2013 Online Published: January 23, 2013

doi:10.5539/enrr.v3n1p127

URL: http://dx.doi.org/10.5539/enrr.v3n1p127

\begin{abstract}
Climate change is a global issue and its impact is felt everywhere by both human and ecosystem. Climate variability and change threaten the well being of humans. This study examines the impact of climate variability on human health with the use of regression, correlation and ANOVA. The result shows that there is a very strong positive correlation between minimum temperature and typhoid (0.844), maximum temperature and malaria $(0,794)$, typhoid (0.793), between sunshine and typhoid (0.667), malaria $(0.630)$. The other variables are weakly correlated with the diseases. The regression analysis reveals that $49 \%, 88 \%$ and $79 \%$ of the variance in asthma, typhoid and malaria can be respectively explained by the climatic parameters under study to a certain extent. This implies that there may be some other factors that are responsible for the selected diseases in the area. Such factors may include biological (genotype, micro-organisms, and allergies), unhygienic environment and economic (poor living conditions). Recommendations made include weather report should be broadcasted to people through the media in order for them to understand variation in the climate and how to adapt and mitigate the effect of the changes. Furthermore, people should be enlightened on the effects of anthropogenic activities in the atmosphere and how to reduce these effects for sustainable development.
\end{abstract}

Keywords: anthropogenic activities, climate change, adaptation, greenhouse gases human health

\section{Introduction}

\subsection{Causes of Climate Variability and Change}

Climate can be defined as the average weather condition or the regular variations in weather in a region over a period of years. Climate variability can be referred to as difference from statistical average of climate over a given period of time (such as a specific month, season or year). The basic characteristic of climate which shows itself very clearly in changes with time is what is regarded as climate variability. While any change in climate which alters the composition of the global atmosphere which is in addition to natural climate variability observed over comparable time periods is what is regarded to as climate change. The most acceptable definition of climate change was given by IPCC (2007) Fourth Assessment Report (AR4) as a change in the state of the climate that can be identified (e g. using statistical tests) by changes in the mean and/or the variability of its properties, and that persists for an extended period typically decades or longer.

Climate variability and change are caused essentially by natural and anthropogenic activities. The natural activities include interaction of the oceans and the atmosphere, changes in the earth's orbit, changes in the energy received from the sun and volcanic eruptions. Very recently, there was a consensus that anthropogenic activities constituted the major cause of climate change. Human-induced alterations of the natural world have contributed to the high increase in the rate of gaseous emissions into the atmosphere, thereby causing global warming. Past studies (Buba, 2004; Porbeni, 2004; DeWeerdt, 2007; Odjugo, 2007) over decades have revealed that anthropogenic activities like urbanization, population explosion, deforestation, industrialization and the release of greenhouse gases contribute highly to the depletion of the ozone layer and its associated global warming, climate variability and change. The World Health Organization (WHO) estimates that about 150,000 deaths annually (especially in African countries) are attributable to climate change. This study therefore examines the impact of climate variability and change on human health in Ilorin, Nigeria.

\subsection{The Study Area}

Ilorin the state capital of Kwara state, Nigeria is the study area of this research and it is located on latitude $8^{\circ} 30^{\prime}$ and $8^{\circ} 50^{\prime} \mathrm{N}$ and longitude $4^{\circ} 20^{\prime}$ and $4^{\circ} 35^{\prime} \mathrm{E}$ of the equator (Figure 1). Ilorin city occupies an area of about 468 
sqkm and it is situated in the transitional zone within the forest and the guinea savannah regions of Nigeria. It is about 300 kilometers away from Lagos and 500 kilometers away from Abuja the federal capital of Nigeria. The climate of Ilorin is tropical under the influence of the two trade winds prevailing over the country. Ilorin metropolis experiences two climatic seasons i.e. rainy and dry season. The rainy season is between March and November and the annual rainfall varies from $1000 \mathrm{~mm}$ to $1500 \mathrm{~mm}$, with the peak between September and early October. Also, the mean monthly temperature is generally high throughout the year (Ajibade, 2002). The daily average temperatures are in January with $25^{\circ} \mathrm{C}$, May $27.5^{\circ} \mathrm{C}$ and September $22.5^{\circ} \mathrm{C}$.

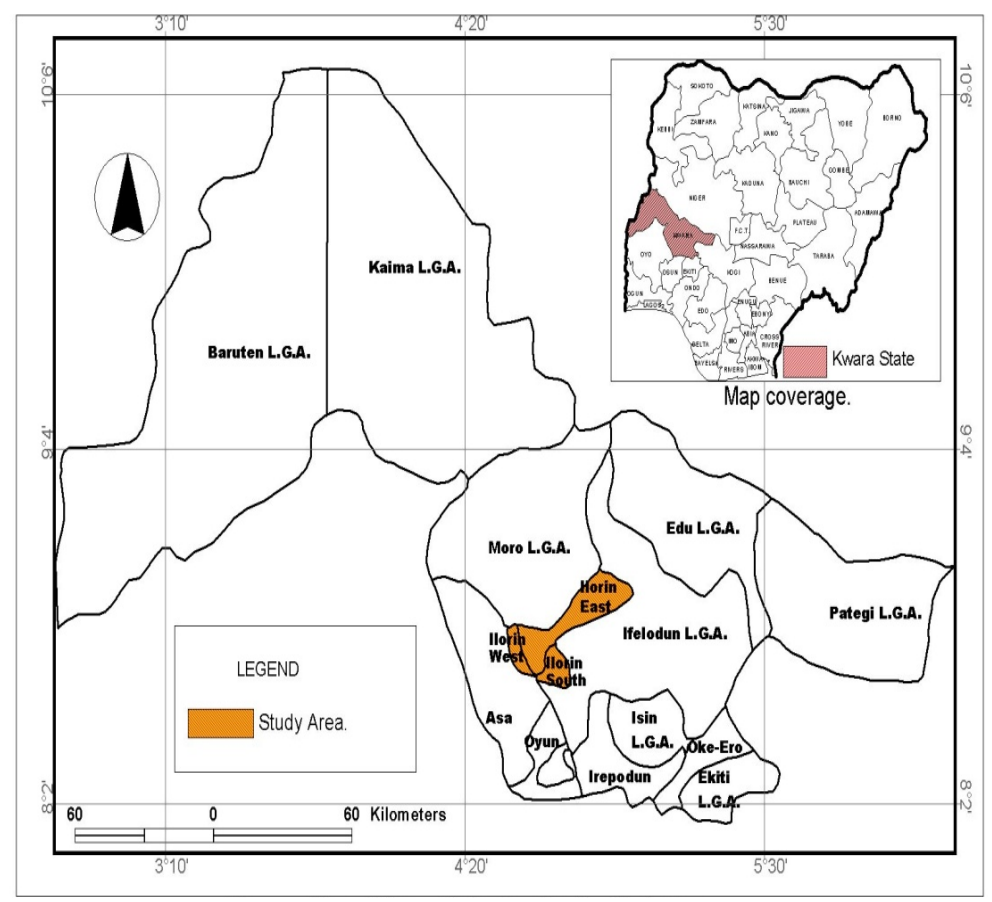

Figure 1. Map of Kwara State showing the study area

The vegetation type found here is derived savannah with riparian forest along the river bank. The drainage system of Ilorin is dendritic in pattern due to its characteristics. The most important river is Asa River which flows in south-northern direction. Asa River occupies a fairly wide valley and goes a long way to divide Ilorin into two parts namely the Eastern and the western part .The major rivers are Asa, Agba, Alalubosa, Okun, Osere and Aluko. Some of these rivers drain into river Niger or river Asa (Oyegun, 1986). The general elevation of land on the western part varies from $273 \mathrm{~m}$ to $364 \mathrm{~m}$ (i.e. 900 to $1 / 200 \mathrm{ft}$ ) above sea level. To the north of the western part of Ilorin exists an isolated hill known as Sobi hill which is about $394 \mathrm{~m}$ high above sea level. Majority of the land surface of Ilorin are as high as $100 \mathrm{~m}$ above sea level with the highest point having $1300 \mathrm{~m}$ above sea level. The geology of the study area consists of Precambrian basement complex rock. The population of Ilorin (see Table 1) in 1953 was 40,994 and by 1963 census, it was 208,546. This shows a great increment. The 1991 census put the population of Ilorin at 570,000. It is very much clear that there is a considerable increase in the size of Ilorin in terms of population of the years. The population was projected with an annual growth rate of $2.84 \%$ to reach 606,533 by the year 1996 (NPC, 1991). The 2006 census put the population at 766,000 (NPC, 2006). The increase in population in Ilorin has led to a number of problems such as housing congestion and accommodation problem which has forced a lot of people to live in uncongenial environment. Associated with this, is industrialization and erratic power supply which led an upsurge in the use of electricity generating plants. Also, the number of vehicles on the road has increased, all of which led to increased emission of carbon-monoxide and carbon dioxide. The implication of these is environmental pollution and this has been described as the contamination of the environment by biological, chemical, and or physical agents that are harmful to human, animal or plant, life and the general environment, and may arise through the natural events, industrial and human activities or the interaction of all. 
Table 1. Population growth trend in Ilorin 1953-2006

\begin{tabular}{llll}
\hline Year & Population & Rate of Change in population & \% Rate of Change in Population \\
\hline 1953 & 40,994 & 4,647 & 5.3 \\
1963 & 208,546 & 167,556 & 21.9 \\
1982 & 474,835 & 266289 & 34.8 \\
1984 & 480,000 & 5165 & 0.7 \\
1991 & 570,000 & 90,000 & 11.7 \\
2006 & 766,000 & 196,000 & 25.6
\end{tabular}

Source: Oyebanji, 1993; NPC, 2006 adapted from (Adeleke, 2009).

\subsection{Climate Variations and Health}

Climate change affects human health (Table 2) directly or indirectly in many ways. For instance, increasing temperatures, rising sea levels and increasing storm frequencies have great implication on human health in the area of injury and illness. During rainy season, there is a rise in the sea and ocean levels as a result of global warming. Hence, flooding may result which is likely to increase the vulnerability of the poor to malaria, typhoid, cholera and pneumonia. Also, temperature and rainfall dynamics may increase the distribution of disease vectors such as dengue, malaria and incidence of diarrheal diseases (Haines et al., 2006). Urban floods experienced by people can make them suffer mental disorders, spread diseases, destroy houses, assets and interrupt schooling. Harsh weather conditions especially in the northern part of Nigeria often lead to different diseases. Stagnated water (Figure 2) as a result of heavy rainfall often breeds mosquitoes which cause malaria to the people living around the area. According to Persinger (1980) human comfort is usually affected by humidity and the understanding of temperature is largely dependent upon atmospheric moisture content. The Guardian Newspaper of $30^{\text {th }}$ March 2010 reported that within one week in the early 2009 over 200 people were killed by meningitis in Nigeria and Niger Republic. The indirect effects although difficult to specify may include: Diseases carrying vectors, increased psychological stress and depression, feeling of isolation amongst displaced people due to natural disasters, rising sea levels and displacement of people from their natural habitats and the attendant effects. Extreme weather events amplifies the spread of pests and diseases and whenever temperature is high there is tendency for increased ailments such as meningitis, measles, chicken pox to mention just a few. The asthma information guide.com (2000) agreed that weather and the environment play an important role in asthma attack and temperature influences asthma more than any weather factors.

Table 2. Health effects of climate change

\begin{tabular}{|c|c|}
\hline Direct & \\
\hline \multirow{8}{*}{ Indirec } & Deaths and illness due to thermal extremes \\
\hline & Injury resulting from floods and storms \\
\hline & \\
\hline & More widespread vector - borne infections \\
\hline & Increase in other infectious diseases \\
\hline & Respiratory effects of worsening air pollution \\
\hline & Poor nutrition due to agricultural disruption \\
\hline & Ill-health due to social dislocation and migration \\
\hline
\end{tabular}

Source: Woodward et al. (1998) adapted from Orire and Olorunfemi (2009). 


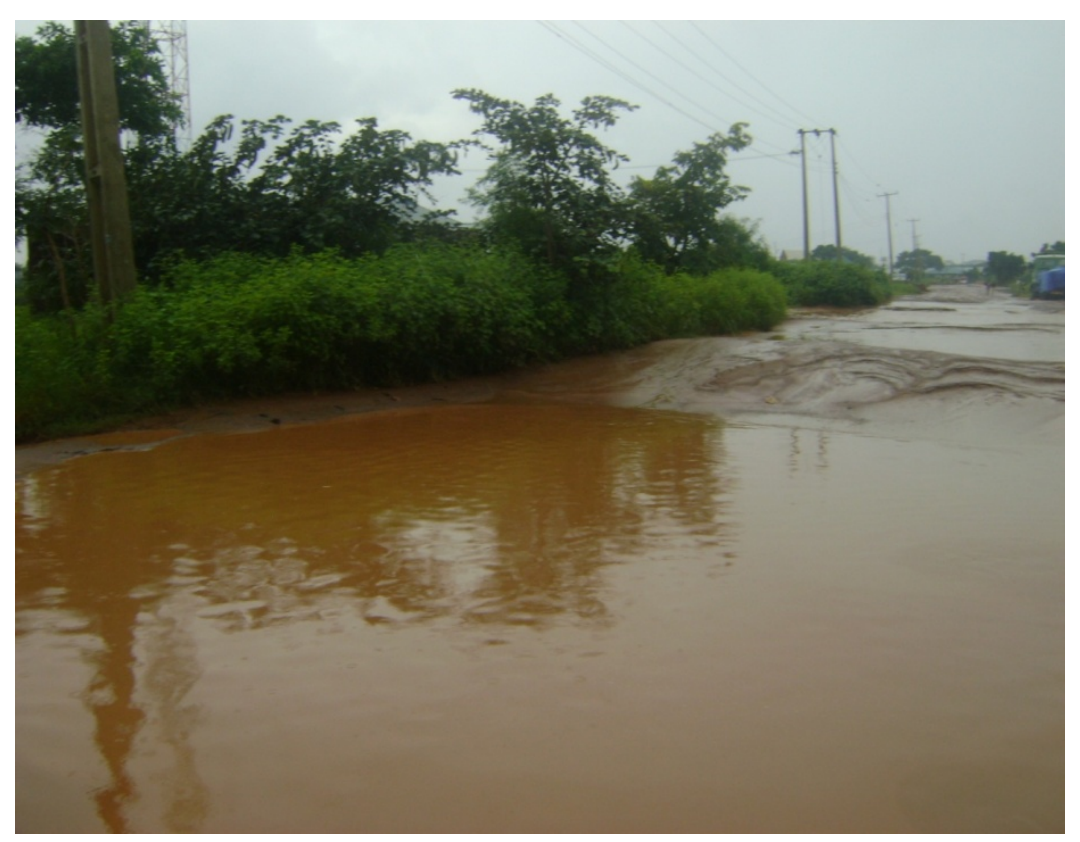

Figure 2. Stagnate water on the road in Ilorin after a heavy downpour

Source: Field work, 2012.

Olorunfemi and Adeyemi (1994) in their attempt to find out the relationship between climate and the major causes of mortality in Ilorin found out that deaths are common in rainy season. Similarly, some vector borne diseases like malaria, fever and dengue fever transmission are highest in month of heavy rainfall and humidity (More, 1992). Heavy rainfall events can also carry terrestrial micro-biological agents into drinking water sources which eventually led to outbreak of cryptosporidiosis, giardiasis, amoebiasis, typhoid and other infections (Lisle, 1995; Rose, 2000).

Recent evidences showed that typhoid is mostly triggered in high temperature and increased humidity which are the proof of climate change. Burton (1993) found out that there is extensive evidence that an extreme climatic event will result in higher losses of life in a developing countries than in the developed countries as a result of coping ability and poor environmental planning. This implies that human health is a function of climatic variables. More (1992) agreed that some vector borne-diseases e.g. malaria and dengue fever show significant seasonal pattern whereby transmission is high in the month of heavy rainfall and humidity.

\section{Research Methods}

Secondary data were obtained from the University Teaching Hospital and NIMET office on selected diseases and climatic data of Ilorin respectively. The selected diseases include asthma, malaria and typhoid fever while the climatic data are rainfall, relative humidity, maximum and minimum temperature and sunshine for a period of ten 10 years (2002-2011). Correlation, regression analysis and Analysis of Variance (ANOVA) were employed to analyze the data in order to establish a relationship between climatic data and selected diseases and also, to show the percentage contribution of the variables to the selected diseases. The regression equation is written as $\mathrm{Y}=\mathrm{a}+\mathrm{b}_{1} \mathrm{x}_{1}+\mathrm{b}_{2} \mathrm{x}_{2}+\mathrm{b}_{3} \mathrm{x}_{3}+\mathrm{e}$. where

$\mathrm{Y}=$ climatic data

$\mathrm{X}_{1}=$ asthma

$\mathrm{X}_{2}=$ typhoid

$\mathrm{X}_{3}=$ malaria

$\mathrm{e}=$ error term

\subsection{Results and Discussions}

Table 3 shows the trend of climatic data in the study area over a period of ten (10) years. Significant differences existed in maximum temperature in the year 2010 and 2011. Rainfall also decreased in the year 2010 and 2011 
while there are no significant differences in minimum temperature, relative humidity and sunshine over the years sampled.

Table 3. Climatic data of Ilorin between 2002 and 2011

\begin{tabular}{llllll}
\hline Year & $\operatorname{Max} \operatorname{Temp}\left({ }^{\circ} \mathrm{C}\right)$ & $\operatorname{Mini} \mathrm{Temp}\left({ }^{\circ} \mathrm{C}\right)$ & Rainfall $(\mathrm{mm})$ & $\mathrm{R} / \mathrm{H}(\%)$ & Sunshine(hr) \\
\hline 2002 & 32.62 & 21.80 & 79.90 & 72.75 & 5.76 \\
2003 & 32.80 & 21.93 & 129.47 & 74.83 & 5.95 \\
2004 & 32.8 & 22.07 & 117.80 & 75.6 & 6.18 \\
2005 & 32.4 & 22.13 & 108.82 & 74.75 & 6.18 \\
2006 & 32.23 & 21.66 & 117.42 & 76.58 & 6.32 \\
2007 & 32.67 & 21.82 & 109.09 & 73.83 & 6.38 \\
2008 & 32.00 & 22.38 & 122.37 & 70.83 & 6.53 \\
2009 & 32.76 & 22.00 & 111.87 & 78.92 & 6.27 \\
2010 & 55.29 & 22.41 & 86.65 & 78.00 & 6.62 \\
2011 & 55.54 & 22.48 & 89.64 & 78.58 & 6.86
\end{tabular}

Source: NIMET (2012).

From Table 4, it can be deduced that reported cases of people with asthma is very high in the year 2005. The year 2010 and 2011 recorded high number of people with typhoid fever. Also, between the year 2007 and 2011, reported cases of people with malaria is very high except for a slight reduction in the year 2008.

Table 4. Record of the selected diseases between 2002 and 2011(Average number of people per year)

\begin{tabular}{llll}
\hline Year & Asthma & Typhoid & Malaria \\
\hline 2002 & 75 & 142 & 218.75 \\
2003 & 84 & 139 & 141.83 \\
2004 & 70 & 148 & 143.92 \\
2005 & 108 & 145 & 130.00 \\
2006 & 65 & 134 & 137.25 \\
2007 & 89 & 140 & 285.75 \\
2008 & 97 & 152 & 190.33 \\
2009 & 82 & 130 & 201.75 \\
2010 & 71 & 157 & 324.40 \\
2011 & 79 & 169 & 330.30 \\
\hline
\end{tabular}

Source: UITH 2012.

\subsection{Correlation between Selected Diseases and Climatic Variables}

Table 5 shows the correlation between climatic variables and selected diseases. The result of correlation analysis shows multivariate relationship between the climate variability/change and human health, considering the climate variables and selected diseases. This means that maximum temperature $(0.793)$, minimum temperature $(0.844)$, relative humidity $(0.108)$ and sunshine hours $(0.667)$ with rainfall $(-0.454)$ are proportionately related with typhoid fever in exception of rainfall that is inversely related to this disease. An incidence of typhoid is of increase with increase in values of these weather variables but downward trends of rainfall. 
Table 5. Correlation analysis

\begin{tabular}{llcccc}
\hline Disease & Rainfall $(\mathrm{mm})$ & Maximum Temperature & Minimum Temperature & Relative Humidity & Sunshine \\
\hline Malaria & -0.692 & 0.794 & 0.487 & 0.322 & 0.630 \\
Asthma & 0.254 & -0.286 & 0.242 & -0.449 & -0.003 \\
Typhoid & -0.454 & 0.793 & 0.844 & 0.108 & 0.667 \\
\hline
\end{tabular}

Source: Researchers' computation. Correlation is significant at the 0.05 level (2-tailed).

On the incidence of malaria fever, all the weather variables bring about the increase rate of the ailment with exception of rainfall which is inversely related with upward trend of malaria. Maximum temperature (0.794), minimum temperature $(0.487)$, relative humidity $(0.322)$, sunshine hours $(0.630)$ and rainfall $(-0.692)$, explaining that the main climatic elements that induce malaria are temperature, relative humidity and sunshine hours. These elements are lethal to mosquitoes and the parasites because where temperatures are close to the physiological tolerance limit of the parasites, a small temperature increase would be lethal to the parasite and malaria transmission would therefore decrease. At low temperatures, a small increase in temperature will greatly increase the risk of malaria transmission. Moreover, when the temperature increases, the incidence of malaria would increase irrespective of rainfall amount or the duration on the surface. Mosquitoes only take the advantage of stagnant water or pool of water in the environment as a breeding ground but when there is decrease in temperature below the threshold of survival, the mosquitoes will die off, reducing the morbidity at such period of time.

Asthma attack is of inverse correlation with some climatic elements while proportionately correlated with other elements. For instance, the result revealed that maximum temperature $(-0.286)$, relative humidity $(-0.449)$ and sunshine hours $(-0.003)$ are inversely related with incidence of asthma while rainfall $(0.254)$ and minimum temperature $(0.242)$, are proportionately related with asthma. Maximum temperatures always increase heat content as a result of surface absorption of solar radiation in the day hours, usually resulted to convection rainfall. At this period, the atmosphere is moist with little or no pollen grain or dust particles that do trigger asthma attack among the patients during horizontal air motion. This could however explain the inverse correlation between these variables and asthma.

\subsection{Regression Analysis for the Selected Diseases and Climatic Variables}

Table 6 shows that $49 \%, 88 \%$ and $79 \%$ of the variance in asthma, typhoid and malaria can be respectively explained by the climatic parameters under study. Climatic variables therefore to some extent, have impact on selected diseases over the years under study. This is because climate change has a significant and profound influence on physiological comfort and health behaviours of people. However, Ayoade (2004) observed that not all effects of climate on human are negative because favourable climatic conditions can help human body in wading off certain diseases and enhances recuperation from illness.

Table 6. Regression analysis for the diseases and climatic variables

\begin{tabular}{lllll}
\hline Diseases & $\mathrm{R}$ & $\mathrm{R} 2$ & Adjusted R & Std error of the estimate \\
\hline Asthma & 0.702 & 0.493 & -0.141 & 14.09 \\
Typhoid & 0.939 & 0.882 & 0.734 & 5.93 \\
Malaria & 0.894 & 0.799 & 0.549 & 52.29 \\
\hline
\end{tabular}

Predictors: (constant), Sunshine, Rainfall, RH, Min. temperature and Max temperature.

This implies that the remaining $51 \%, 12 \%$ and $21 \%$ of the variance in asthma, typhoid and malaria can be respectively explained by other factors not included in the study. Such factors include biological (genotype, micro-organisms, and allergies), unhygienic environment and economic (poor living conditions) that are responsible for incidence of disease in the study area. 
Table 7. Analysis of variance

\begin{tabular}{lll}
\hline Dependent variables & F-ratio & Ftable \\
\hline Asthma & 0.777 & 0.613 \\
Typhoid & 5.976 & 0.054 \\
Malaria & 3.189 & 0.142 \\
\hline
\end{tabular}

Predictors: (constant), Sunshine, Rainfall, RH, Min. temperature and Max temperature.

$\mathrm{H}_{\mathrm{o}}$ : Climate variability has no significant impact on human health.

$\mathrm{H}_{1}$ : Climate variability has significant impact on human health.

Decision Rule: Reject $\mathrm{H}_{\mathrm{o}}$ when F-ratio is greater than $\mathrm{F}_{\text {table }}$ or otherwise.

From the result on Table 7, $\mathrm{H}_{\mathrm{o}}$ is rejected and while the alternative hypothesis $\left(\mathrm{H}_{1}\right)$ that climate change has significant impact on human health is accepted since F-ratio on asthma (0.777), typhoid (5.976) and malaria (3.189) are greater than F-table i.e. $0.613,0.054$ and 0.142 respectively. The implication of this result is that incidence of these prevalent ailment in Ilorin to some extent is a function of climate variability/change. As the temperature increases, weather condition tends to dry with increase in pollen grain and dust particles in the atmosphere low relative humidity and increase moisture in the sky which directly provokes asthma in some patients.

Typhoid fever and malaria are mainly pronounced during hot weather as majority of people do come down with these diseases. As the temperature increases, cases of malaria increase because the breeding capacity of mosquitoes that transmit malaria vectors will increase at low relative humidity and low rainfall will give rise to mosquitoes bite. This finding is similar to the work of Githeko and Ndegwa (2001) in highland of Karamega that there is a close association between malaria transmission and monthly temperature. Typhoid fever is linked with environmental factors like water pollution during which period the streams might have been contaminated with run off.

\section{Conclusion and Policy Implications}

The study has actually revealed that variations in climatic variables such as rainfall, maximum and minimum temperature, relative humidity and sunshine to a certain extent affect human health in the study area. However, there are some other factors that contributed to the incidence of these diseases but were not included in the study. Therefore in order to mitigate the effects of climate variability/change on human health there is the need to assess vulnerabilities as well as identify adaptation options in other related human health sectors. People should be educated and informed on how climate variability and change affect human health generally. The use of mosquito nets, clearing stagnate water and not residing near riverbeds will also mitigate the effect of climate variability in the study area. Weather report should be broadcasted to people through the media in order for them to understand variation in the climate and how to adapt and mitigate the effect of the changes. Furthermore, people should be enlightened on the effects of anthropogenic activities in the atmosphere and how to reduce these effects for sustainable development.

\section{References}

Action Aid. (2006). Climate Change, Urban flooding and the rights of the urban poor in Africa: key findings from six African cities. Action Aid, October, 2006.

Adeleke, E. A. (2009). The Effect of Climate on Human Health in Ilorin. Unpublished M.Sc Dissertation, Department of Geography and Environmental Management, University of Ilorin, Nigeria.

Ajibade, L. T. (2002). Indigenous Systems of Land Evaluation in the Yoruba Speaking Area of Kwara State. Unpublished Ph.D Thesis. Obafemi Awolowo University (OAU), Ile-Ife, Osun State, Nigeria.

Ayoade, J. O. (2004). Introduction to Climatology for the Tropics. Spectrum Books Ltd., Ring Road, Ibadan.

Buba, A. D. (2004). Climate change and water problems in Chad Republic. Journal of Arid Environment, 3(2), 42-50.

Burton, I. (1993). The Environment as hazard. New York, USA: The Guilford Press.

DeWeerdt, S. (2007). Climate change coming home: Global warming effect on populations. World Watch, 2(3), 6-13. 
Githeko, A., \& Ndegwa, W. (2001). Predicting Malaria Epidemics in the Kenyan Highlands using Climate Data: A tool for Decision Maker. Global Change and Human Health, 2, 54-63. http://dx.doi.org/10.1023/A:1011943131643

Haines, A., Kovats, R. S. D., Campbell-Lendrumb, C., \& Corvalan, C. (2006). Climate Change and Human Health: Impacts, Vulnerability and Public Health. Journal of the Royal Institute of Public Health, 120, 585-596.

Intergovernmental Panel on Climate (IPCC). (2007). Climate change 2007: Synthesis Report. Summary for policy makers. pp. 1-22. Retrieved from October 26, 2009, http://www.ipcc-wg1-ucar.edu/wg1/wg1-report.htm

Lisle, J. T. (1995). Cryptosporidium contamination of water in the US and UK: A Mini-review. Aqua, 44, 103-117.

More, G. (1992). Epidemiology and Treatment of Cyclosporine Cayetanesis Infection in Peruvian Children. Clinical Infectious Diseases, 24(5), 977-981.

National Population Commission. (1991). Census News Publication, 3(1), Lagos Nigeria.

National Population Commission. (2006). Population Census of the Federal Republic of Nigeria: Analytical Report of the National level, NPC, Abuja.

Odjugo, P. A. O. (2007). The Impact of Climate Change on Water Resources; Global and Regional Analysis. Indonesian Journal of Geography, 39(1), 23-41.

Olorunfemi, J. F., \& Adeyemi, A. S. (1994). Climate and Mortality in Ilorin (1983-1992). Ilorin Journal of Business and Social Sciences, 4.

Orire, I. O., \& Olorunfemi, J. F. (2009). Global Warming and Human Health. A Paper Presented at the University of Cape Coast and University of Ilorin International Conference on 'Culture, Science and Sustainable Development in Africa' on $28^{\text {th }}-30^{\text {th }}$ September, 2009.

Oyegun, R. O. (1986). The Use and Waste of Water in a Third World city: A Case of Ilorin Metropolis. Geojournal, 10(2), 210.

Persinger, M. A. (1980). The Weather Matrix and Human Behavior, p. 327. New York: Praeger,

Porbeni, C. V. (2004). The impact of Global Warming on High Latitudes and Attitudes. Journal of Arid Environment, 3(2), 75-88.

Rose, J. B. S. (2000).Climate and Water-borne Outbreaks in the U.S A preliminary descriptive analysis. Journal of the American Water works Association, 92, 1194-1199.

The asthma information guide.com. (2000). Asthma.

The Guardian Newspaper. (2010). Heat, Dusty Weather Raise Health Concerns. Climate Change Effects in Nigeria. $30^{\text {th }}$ March, 2010. 